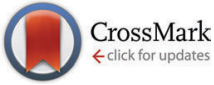

Cite this: Chem. Commun., 2016, 52,5880

Received 9th March 2016, Accepted 29th March 2016

DOI: $10.1039 / c 6 c c 02108 e$

www.rsc.org/chemcomm

\section{Unveiling the first indole-fused thiazepine: structure, synthesis and biosynthesis of cyclonasturlexin, a remarkable cruciferous phytoalexin $\dagger$}

\author{
M. S. C. Pedras* and Q. H. To
}

\begin{abstract}
As a mechanism of defense against pathogens and other types of stress, watercress plants produce a variety of elicited chemical defenses generally known as phytoalexins. Herein the chemical structure, synthesis, biosynthesis and antifungal activity of cyclonasturlexin, the most intriguing indolyl phytoalexin isolated to date, are reported.
\end{abstract}

To complete their natural life cycle, from seed to flower to seed, flowering plants have to cope with stress and enemies. Enemies such as microbes and insects are overcome or partially deterred by physical barriers and an array of organic compounds known as secondary metabolites. Antimicrobial secondary metabolites produced by plants under stress inflicted by microbial pathogens, heavy metals or UV radiation are called phytoalexins. ${ }^{1}$ That is, phytoalexins are a group of elicited plant metabolites with vital ecological roles related to defence, usually not detected in healthy plants. The structural variety of phytoalexins correlates with both the diversity of plant families and species within a particular family. Within the family Brassicaceae (containing more than 3700 species commonly known as crucifers) phytoalexins have "one of a kind" chemical structures that are biosynthetically derived from $(S)$-tryptophan $\left(S\right.$-Trp). ${ }^{2}$ For example, while the cruciferous phytoalexins brassinins (1-3) contain 3-methylindole attached to an $S$-methyl dithiocarbamate, cyclobrassinin (4), rutalexin (5) and brassilexin (6) are tricyclic [b]indole-fused compounds, and rapalexin A (7) and isocyalexin A (8) ${ }^{3}$ are 3 -substituted indoles. ${ }^{2} S$-Trp is a primary metabolite common to most living organisms, including microbes and animals. The biosynthetic relationship between $S$-Trp and phytoalexins 1-8 is summarized in Scheme 1.

Economically important crucifer species are sources of edible oils and vegetables such as Brussels sprouts, broccoli, cabbage, kale, cauliflower, turnip and rutabaga. ${ }^{4}$ Crucifer vegetables are beneficial to human diet partly due to their anticarcinogenic properties.

Department of Chemistry, University of Saskatchewan, 10 Science Place,

Saskatoon SK S7N 5C9, Canada.E-mail: s.pedras@usask.ca

$\dagger$ Electronic supplementary information (ESI) available: Synthesis, biosynthesis, characterization and NMR spectra of new compounds. CCDC 1456343. For ESI and crystallographic data in CIF or other electronic format see DOI: 10.1039/c6cc02108e

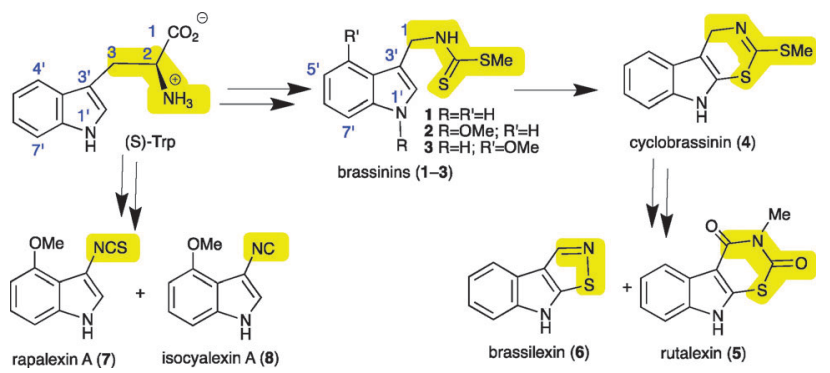

Scheme 1 Biosynthetic relationship of S-tryptophan (S-Trp) with cruciferous phytoalexins $\mathbf{1 - 8}$ (two arrows indicate multiple transformations).

The crucifer watercress (Nasturtium officinale R. Br.) was recently shown to produce brassinin (1) together with a novel class of phytoalexins called nasturlexins A (9) and B (10), and tridentatol $\mathrm{C}(\mathbf{1 1}) .^{5}$ That is, watercress was the first crucifer species reported to synthesize phytoalexins from two parallel pathways that result from $S$-Trp (1-8) and phenylalanine (9-11). Further work on stressed watercress plants has unveiled perhaps the most exceptional of all cruciferous phytoalexins, the first ever known indolefused 1,3-thiazepine that we called cyclonasturlexin (15). Herein the structure, synthesis, biosynthesis and antifungal activity of this alkaloid are disclosed.

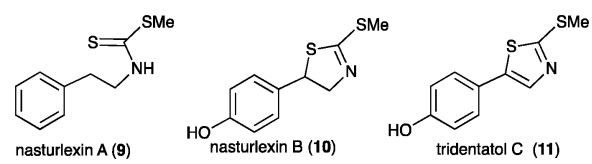

Typically, phytoalexin production in leaves of watercress was detected and quantified after elicitation with $\mathrm{CuCl}_{2} \cdot{ }^{5}$ Additional elicitation experiments of whole plants using either UV radiation or $\mathrm{CuCl}_{2}$ followed by HPLC-DAD-ESI-MS analysis, and comparison of chromatograms with those of control plants, showed a constituent detected only in extracts of elicited leaves, in addition to nasturlexin B (10) (Fig. 1, $t_{\mathrm{R}}=21.9$ min; Fig. S1, S2 and Table S1, ESI $\dagger$ ). UV-ESIMS data suggested that this new constituent X (HPLC-DAD, $220 \mathrm{~nm}$ ) was not available in our virtual libraries of plant metabolites. 


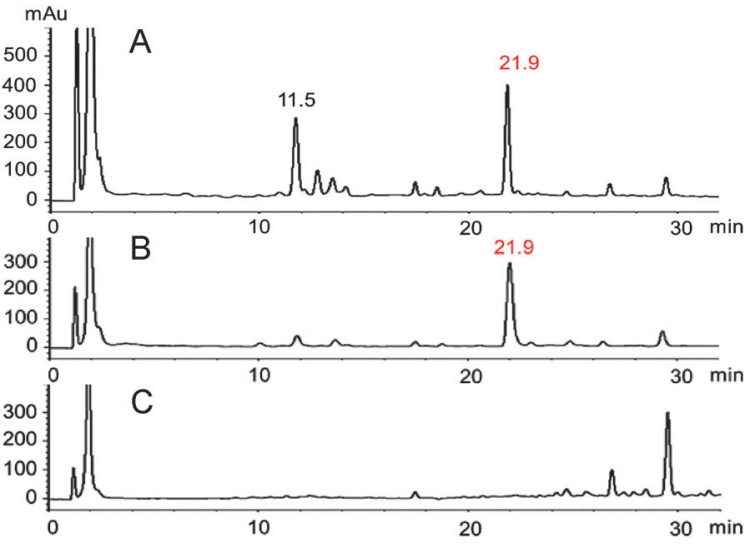

Fig. 1 HPLC-DAD $(220 \mathrm{~nm})$ chromatograms of extracts of leaves of watercress 48 hours post-elicitation with: (A) $\mathrm{CuCl}_{2}$; (B) UV radiation; (C) control; elicited metabolites: $t_{R}=11.5 \mathrm{~min}$, nasturlexin $\mathrm{B}(\mathbf{1 0}) ; t_{R}=21.9 \mathrm{~min}$, metabolite X (15).

Isolation of metabolite $\mathrm{X}$ from combined hexane and EtOAc extracts (ca. $1.7 \mathrm{~g}$ ) of elicited leaves afforded $c a .4 \mathrm{mg}$, as summarized in the $\mathrm{ESI}^{\dagger}+$ (Fig. S3). The HR-EI-MS data of this constituent suggested a molecular formula (calc. for $\mathrm{C}_{11} \mathrm{H}_{10} \mathrm{~N}_{2} \mathrm{~S}_{2}$ : 234.0285, found 234.0282) identical to that of cyclobrassinin (4), whereas its ${ }^{1} \mathrm{H}$ NMR spectroscopic data $\left(\mathrm{CDCl}_{3}\right)$ suggested a different indolyl moiety. That is, the four aromatic signals at $\delta 7.13(\mathrm{~d}, 8.0 \mathrm{~Hz}, 1 \mathrm{H})$, $7.03(\mathrm{~m}, 2 \mathrm{H}), 6.89(\mathrm{~d}, 7.5 \mathrm{~Hz}, 1 \mathrm{H})$ plus two methylene protons at $\delta 5.13(\mathrm{~s}, 2 \mathrm{H})$ and an $S-\mathrm{CH}_{3}$ substituent at $\delta 2.36(\mathrm{~s}, 3 \mathrm{H})$ were indicative of a 3,4-disubstituted indole-containing tricyclic system. However, these data could not distinguish between potential chemical structures of indole-fused pyrroles 12 and 13 or indolefused 1,3-thiazepines 14 and 15. Biosynthetic consideration suggested that metabolite $\mathrm{X}$ was likely derived from brassinin (1), hence structures 12 and $\mathbf{1 5}$ were thought to be more likely than their regioisomers 13 and 14.

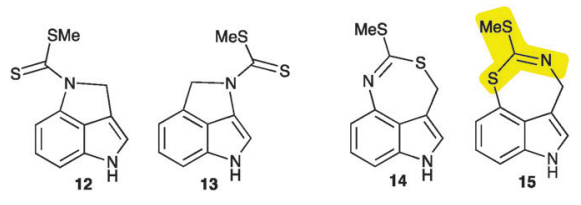

The final structural proof was obtained by X-ray crystallographic analysis of a single crystal of X (Fig. S4, ESI $\dagger$ ). Metabolite $\mathrm{X}$ possesses structure 15, a new indole-fused 1,3-thiazepine heterocycle that has not been reported to date, including online databases such as SciFinder or Chemspider.

Next, it was necessary to devise a synthetic route to metabolite 15, particularly due to the insufficient amount obtained from a rather large amount of extract (Fig. S3, ESI $\dagger$ ). A biomimetic synthesis of $\mathbf{1 5}$ was thought to be possible using the intramolecular cyclization of the key intermediate 4-iodobrassinin (16), accessible from indole-3-carboxaldehyde (18), as outlined in Scheme 2. 4-Iodobrassinin (16) was prepared from indole-3carboxaldehyde (18) (Scheme S1, ESI $\dagger$ ).

Efforts to cyclize 4-iodobrassinin (16) to 15 were inspired by the synthesis of methyl chuangxinmycin (20). Namely,

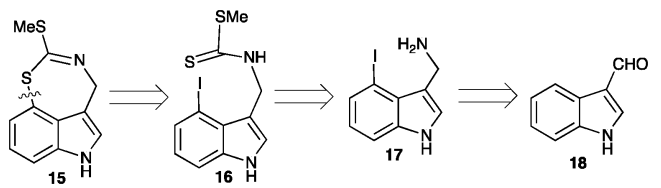

Scheme 2 Retro-synthetic analysis of metabolite 15 from commercially available indole-3-carboxaldehyde (18).

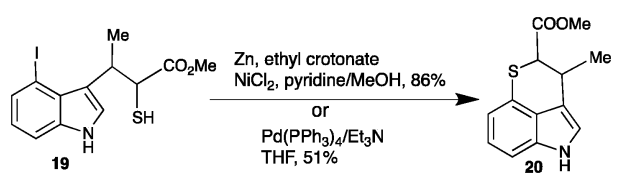

Scheme 3 Synthesis of the methyl ester of chuangxinmycin (20): C-S intramolecular coupling of thiol with 4-iodo-indole using $\mathrm{Ni}(0) \cdot 2 \mathrm{EC} \cdot \mathrm{Py}$ in $\mathrm{MeOH}^{6}$ or $\mathrm{Pd}\left(\mathrm{PPh}_{3}\right)_{4} / \mathrm{Et}_{3} \mathrm{~N}$ in $\mathrm{THF}^{7}$

the intramolecular cyclization of methyl 2-sulfanyl-3-(4-iodo- $1 H^{-}$ indol-3-yl)-butanoate (19) using either $\mathrm{Ni}(0) \cdot 2 \mathrm{EC} \cdot \mathrm{Py}$ (generated in situ from a mixture of $\mathrm{Zn} / \mathrm{NiCl}_{2} /$ pyridine/ethyl crotonate (EC) $)^{6}$ or $\mathrm{Pd}\left(\mathrm{PPh}_{3}\right)_{4} / \mathrm{Et}_{3} \mathrm{~N}^{7}$ as a catalyst (Scheme 3$)$.

Disappointingly, when 4-iodobrassinin (16) was subjected to $\mathrm{Ni}(0) \cdot 2 \mathrm{EC} \cdot$ Py catalysis, ${ }^{6} \mathbf{1 5}$ was not detected, but 22 was among the several products obtained (Table 1, entry 1). Similarly, 4-iodobrassinin (16) treated with $\mathrm{Pd}\left(\mathrm{PPh}_{3}\right)_{4} / \mathrm{Et}_{3} \mathrm{~N}^{7}$ afforded 22 and unidentified products; removal of $\mathrm{Et}_{3} \mathrm{~N}$ from the reaction medium yielded a lower amount of 22 (entries 2 and 3).

Similar conditions applied to $1-\mathrm{MeSO}_{2}$-4-iodobrassinin (21) afforded products $\mathbf{2 3}$ and $\mathbf{2 4}$ (results not provided). It is likely that isothiocyanate $\mathbf{2 4}$ is formed under basic conditions by elimination of methyl sulphide from 21. Elimination of -NCS from 24 yields carbonium ion $\mathbf{I}-1$ that can react with methyl sulphide to yield 23. These results suggested that 16 and 21 are unstable under these reaction conditions. Hence, alternative cyclization methods to obtain 15 were necessary. C-S bond coupling has been achieved by reacting 2-iodoanilines with carbonotrithioate salts followed by an intramolecular condensation catalysed by $\mathrm{Cu}(\mathrm{I}){ }^{8}$

Alternatively, the $\mathrm{Cu}(\mathrm{I})$-catalysed intramolecular $\mathrm{C}-\mathrm{S}$ bond formation of dithiocarbamate salts (generated from 2-bromo or 2-iodoanilines and carbon disulphide) and subsequent coupling with aryl halides under $\mathrm{Cu}(\mathrm{I})$ catalysis have been reported. ${ }^{9}$ However, application of similar conditions to 4-iodoindolyl-3methyl dithiocarbamate (25) afforded undetermined products. Reasoning that $\mathrm{Cu}(\mathrm{I})$ catalysis could be applied to dithiocarbamate esters as well, 4-iodobrassinin (16) was treated with $\mathrm{CuBr}$ under various conditions. Among the numerous reaction conditions attempted, several afforded the desired compound $\mathbf{1 5}$ (Table 1, entries 5-11).

Rewardingly, increasing the amount of 4-iodobrassinin (16) and using conditions shown in entry 10 provided metabolite 15 (35\%, experimental details in the ESI $\dagger$ ) identical in all respects to the natural product. This is the first synthesis of the novel heterocyclic system 1,3-thiazepin[5,6,7-cd]indole, of which 15 is the first member. Further work is ongoing to improve yields and synthesize additional derivatives to screen antimicrobial activity. 
Table 1 Screening reaction conditions of the intramolecular $\mathrm{C}-\mathrm{S}$ crosscoupling of 4-iodobrassinin (16)

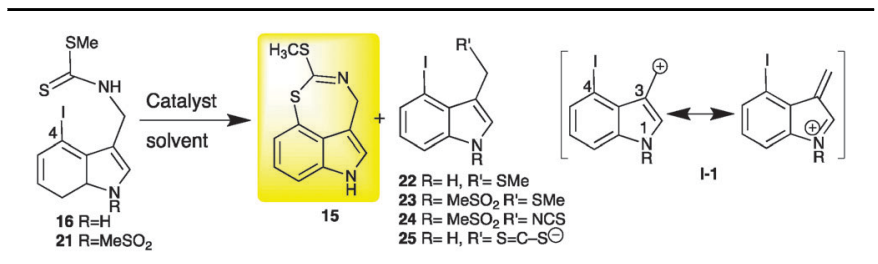

\begin{tabular}{|c|c|c|c|c|c|}
\hline Entry & Catalyst & Solvent & Temp. & $t(\mathrm{~h})$ & $\begin{array}{l}16: 15: 22^{a} \\
(\%)\end{array}$ \\
\hline 1 & $\begin{array}{l}\mathrm{Zn}, \mathrm{NiCl}_{2} \cdot 2 \mathrm{H}_{2} \mathrm{O}(4 \text { eq.), Py, } \\
\text { EC }\end{array}$ & MeOH-Py & $\mathrm{rt}$ & 18 & $0: 0: 70$ \\
\hline 2 & $\mathrm{Pd}\left(\mathrm{PPh}_{3}\right)_{4}(0.05$ eq. $) \mathrm{Et}_{3} \mathrm{~N}$ & THF & $60{ }^{\circ} \mathrm{C}$ & 2 & $0: 0: 83^{b}$ \\
\hline 3 & $\operatorname{Pd}\left(\mathrm{PPh}_{3}\right)_{4}(0.05$ eq. $)$ & THF & $60{ }^{\circ} \mathrm{C}$ & 18 & $47: 0: 51$ \\
\hline 4 & $\mathrm{CuBr}$ (3.0 eq.) & DMF & $55^{\circ} \mathrm{C}$ & 0.5 & $24: 28: 33$ \\
\hline 5 & CuBr (3.0 eq.) & DMF & $55{ }^{\circ} \mathrm{C}$ & 1 & $5: 29: 9$ \\
\hline 6 & $\mathrm{CuBr}(1.0$ eq.) & $\mathrm{DMF}$ & $80{ }^{\circ} \mathrm{C}$ & 0.5 & $14: 20: 0$ \\
\hline 7 & $\mathrm{CuBr}(1.0$ eq.) & DMF & $80{ }^{\circ} \mathrm{C}$ & 1 & $6: 11: 0$ \\
\hline 8 & CuBr (3.0 eq.) & DMF & $80{ }^{\circ} \mathrm{C}$ & 0.16 & $1: 17: 0$ \\
\hline 9 & CuBr (3.0 eq.) & DMF & $80{ }^{\circ} \mathrm{C}$ & 0.33 & $0: 12: 0$ \\
\hline 10 & CuBr (3.0 eq.) & DMSO & $80{ }^{\circ} \mathrm{C}$ & 0.16 & $15: 47: 14$ \\
\hline 11 & CuBr (3.0 eq.) & DMSO & $80{ }^{\circ} \mathrm{C}$ & 0.33 & $0: 23: 0$ \\
\hline
\end{tabular}

${ }^{a}$ Reactions conducted on a $10 \mathrm{mg}$-scale and \% yields quantified by HPLC-DAD (RP-C-18, $220 \mathrm{~nm}$, as described in the ESI) using calibration curves built with authentic synthetic samples. ${ }^{b}$ Isolated yield.

The biological activity of metabolite $\mathbf{1 5}$ toward the plant fungal pathogen Alternaria brassicicola ${ }^{10}$ was evaluated using the growth inhibition assay described in the ESI. $\dagger$ Metabolite 15 displayed high inhibitory activity, causing $87 \%$ of mycelial growth inhibition at $0.15 \mathrm{mM}$, whereas biosynthetically related phytoalexins displayed substantially lower inhibitory activity at $0.20 \mathrm{mM}$ (brassinin (1) 31\%, cyclobrassinin (4) $34 \%$, and brassilexin (6) 59\%) ${ }^{10}$ (Table S2, ESI $\dagger$ ). Because metabolite 15 is produced in plants subjected to stress and displays antimicrobial activity against a microbial pathogen of crucifers, $\mathbf{1 5}$ is a phytoalexin for which we propose the name cyclonasturlexin. Cyclonasturlexin (15) was elicited by spores of $A$. brassicicola in detached leaves of watercress $48 \mathrm{~h}$ after inoculation.

Retro-biosynthetic analysis of the pathway to this unique heterocycle suggests that cyclonasturlexin (15) is derived from $(S)$-Trp via brassinin (1), like cyclobrassinin (4). ${ }^{2}$ To verify this hypothesis, brassinin (1), $\left[{ }^{2} \mathrm{H}_{3} \mathrm{C}-\mathrm{S} 4^{\prime}, 5^{\prime}, 6^{\prime}, 7^{\prime}{ }_{-}^{2} \mathrm{H}_{4}\right]$ brassinin (1a) and $\left[4^{\prime}, 5^{\prime}, 6^{\prime}, 7^{\prime}-{ }^{2} \mathrm{H}_{4}\right]$ brassinin (1b) were synthesized as previously described. ${ }^{2}$ Subsequently, deuterated brassinins 1a and $\mathbf{1 b}$ and $(S)-\left[{ }^{13} \mathrm{C}_{11},{ }^{15} \mathrm{~N}_{2}\right] \operatorname{Trp}$ were administered to leaves of watercress. After $24 \mathrm{~h}$ of incubation, leaves were extracted and the concentrations of brassinin (1), labelled brassinin, cyclonasturlexin (15) and labelled cyclonasturlexin present in each extract were determined by HPLC-DAD (Table 2, calibration curves built with authentic synthetic samples). The percentage of deuterium present in brassinin (1) and cyclonasturlexin (15) was determined by HPLC-ESI-MS (Table 2, Fig. 2 and Fig. S5-S8, ESI $\dagger$ ).

It was established that both perdeutero brassinins $\mathbf{1 a}$ and $\mathbf{1 b}$ were incorporated into cyclonasturlexins (15a and 15b) in ca. 62\% and $57 \%$, respectively, in elicited leaves, while in non-elicited leaves $c a$. 97\% deuterium incorporation was detected (Table 2, entries 1 and 2, Scheme 4). In addition, while cyclonasturlexin was present in substantial amounts in elicited leaves incubated with $1 \mathbf{a}\left(\mathbf{1 5}+\mathbf{1 5 a}, \mathrm{ca} .737 \mathrm{nmoles}^{-1}\right.$ of fresh tissue, entry 1$)$ and 1b $\left(\mathbf{1 5}+\mathbf{1 5 b}, \mathrm{ca} .780\right.$ nmoles $\mathrm{g}^{-1}$ of fresh tissue, entry 2$)$, only traces were detected in non-elicited leaves incubated with $\mathbf{1 a}$

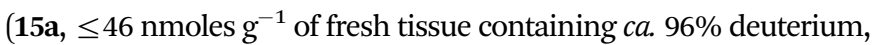
entry 3). By contrast, brassinin (1a) was present in substantially higher amounts in non-elicited leaves (386 nmoles $\mathrm{g}^{-1}$ of fresh tissue containing $\geq 97 \%$ deuterium, entry 3 ) than in elicited leaves (93 and 130 nmoles $^{-1}$ of fresh tissue, entries 1 and 2, respectively). The concentration of cyclonasturlexin in elicited leaves incubated with $(S)-\left[{ }^{13} \mathrm{C}_{11},{ }^{15} \mathrm{~N}_{2}\right]$ Trp was about four fold lower $(15+\mathbf{1 5 c}$, ca. 182 nmoles $\mathrm{g}^{-1}$ of fresh tissue, entry 4) than that in elicited leaves incubated with $\mathbf{1 a}$ or $\mathbf{1 b}$.

These results are consistent with the current understanding of the biosynthetic pathways of brassinin derived phytoalexins. ${ }^{2}$ In elicited leaves (after $24 \mathrm{~h}$ of incubation) the concentration of cyclonasturlexin $(\mathbf{1 5 a}, \mathbf{1 5 b})$ is higher due to the availability and fast conversion of its precursor brassinin (1a or 1b). In nonelicited leaves, due to extremely slow conversion, the concentration of 1a remains much higher.

Consequently, we infer that elicitation of watercress induces the production of a "dedicated" enzyme(s) that catalyses the conversion of $\mathbf{1 a}$ to $\mathbf{1 5 a}$ and $\mathbf{1 b}$ to $\mathbf{1 5 b}$. Furthermore, traces of cyclonasturlexin (15a) and high concentration of $\left[{ }^{2} \mathrm{H}_{3} \mathrm{C}-\mathrm{S}\right.$ $\left.4^{\prime}, 5^{\prime}, 6^{\prime}, 7^{\prime}-{ }^{2} \mathrm{H}_{4}\right]$ brassinin (1a) in extracts of non-elicited leaves are consistent with this conclusion. That is, the amount of the "dedicated" enzyme(s) that catalyses the transformation of 1 to cyclonasturlexin (15) is much lower in non-elicited than in

Table 2 Concentrations ${ }^{a}$ and \% of deuterium ${ }^{b}$ in brassinin (1) and cyclonasturlexin (15) in extracts of leaves of watercress treated with ${ }^{2} \mathrm{H}_{3} \mathrm{C}-\mathrm{S}$ $\left.4^{\prime}, 5^{\prime}, 6^{\prime}, 7^{\prime}-{ }^{2} \mathrm{H}_{4}\right]$ brassinin (1a), $\left[4^{\prime}, 5^{\prime}, 6^{\prime}, 7^{\prime}-{ }^{2} \mathrm{H}_{4}\right]$ brassinin (1b) and $\left[{ }^{13} \mathrm{C}_{11},{ }^{15} \mathrm{~N}_{2}\right] \operatorname{Trp}$

\begin{tabular}{|c|c|c|c|}
\hline Entry & Extracts of leaves of watercress & $\operatorname{Brassinin}^{c}(\mathbf{1} / \mathbf{1 a} / \mathbf{1} \mathbf{b})$ & Cyclonasturlexin $^{c}(\mathbf{1 5}, \mathbf{1 5 a}, \mathbf{1 5 b}, \mathbf{1 5 c})$ \\
\hline 1 & Elicited leaves incubated with $\mathbf{1 a}$ & $\begin{array}{l}93 \pm 60^{d} \\
\geq 97 \%(\mathbf{1 a})^{e}\end{array}$ & $\begin{array}{l}737 \pm 261(\mathbf{1 5}+\mathbf{1 5 a})^{d} \\
62 \pm 17 \%(\mathbf{1 5 a})^{e}\end{array}$ \\
\hline 2 & Elicited leaves incubated with $\mathbf{1 b}$ & $\begin{array}{l}130 \pm 91^{d} \\
\geq 97 \%(\mathbf{1 b})^{e}\end{array}$ & $\begin{array}{l}780 \pm 254(\mathbf{1 5}+\mathbf{1 5 b})^{d} \\
57 \pm 18 \%(\mathbf{1 5 b})^{e}\end{array}$ \\
\hline 3 & Non-elicited leaves incubated with $\mathbf{1 a}$ & $\begin{array}{l}386 \pm 79^{d} \\
\geq 97 \%(\mathbf{1 a})^{e}\end{array}$ & $\begin{array}{l}\leq 46(\mathbf{1 5}+\mathbf{1 5 a})^{d} \\
96 \pm 3 \%(\mathbf{1 5 a})^{e}\end{array}$ \\
\hline 4 & Elicited leaves incubated with $(S)-\left[{ }^{13} \mathrm{C}_{11},{ }^{15} \mathrm{~N}_{2}\right] \operatorname{Trp}$ & $\mathrm{ND}^{f}$ & $\begin{array}{l}182 \pm 31(\mathbf{1 5}+\mathbf{1 5 c})^{d} \\
11 \pm 4 \%(\mathbf{1 5 c})^{g}\end{array}$ \\
\hline 5 & Elicited leaves & $\mathrm{ND}^{f}$ & $166 \pm 42(\mathbf{1 5})^{d}$ \\
\hline
\end{tabular}

${ }^{a}$ Quantified by HPLC-DAD (as described in the ESI). ${ }^{b} \%$ calculated from HPLC-ESI-MS data (as described in the ESI). ${ }^{c}$ DAD detection limits: $\mathbf{1}=0.017 \mathrm{nmol} \mu \mathrm{L}^{-1} ; \mathbf{1 5}=0.01 \mathrm{nmol} \mu \mathrm{L}^{-1} .{ }^{d}$ nmol g${ }^{-1}$ fresh wt. \pm SD of triplicate samples. ${ }^{e} \%$ of deuterium. ${ }^{f} \mathrm{ND}=$ not detected. ${ }^{g} \%$ of ${ }^{13} \mathrm{C}$ and ${ }^{15} \mathrm{~N}$. 


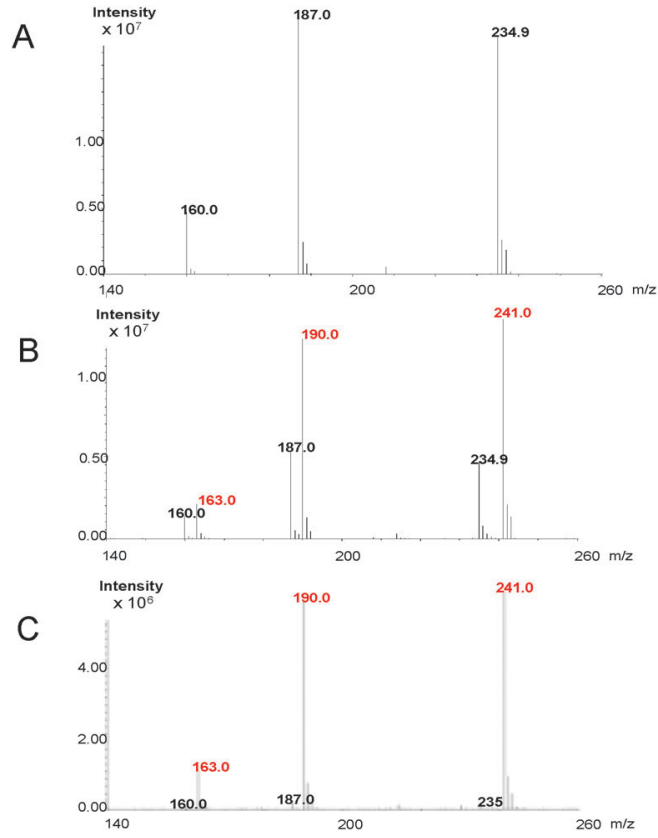

Fig. 2 ESI-MS spectra (positive mode) of cyclonasturlexin (15): (A) natural abundance, $234.9=[\mathrm{M}+1]^{+}, 187=\left[\mathrm{M}-\mathrm{SCH}_{3}\right]^{+}, 160.0=\left[\mathrm{M}-\mathrm{HNCSCH}_{3}\right]^{+}$; (B) elicited - resulting from incorporation of $\left[{ }^{2} \mathrm{H}_{3} \mathrm{C}-\mathrm{S} 4^{\prime}, 5^{\prime}, 6^{\prime}, 7^{\prime}-{ }^{2} \mathrm{H}_{4}\right]$ brassinin (1a), $241.0=[M+1+6]^{+}, 234.9=[M+1]^{+}, 190.0=\left[M+6-S^{2} \mathrm{H}_{3}\right]^{+}, 187=$ $\left[\mathrm{M}-\mathrm{SCH}_{3}\right]^{+}, 163.0=\left[\mathrm{M}+6-\mathrm{HNCSC}^{2} \mathrm{H}_{3}\right]^{+}, 160.0=\left[\mathrm{M}-\mathrm{HNCSCH}_{3}\right]^{+} ;(\mathrm{C})$ nonelicited - resulting from incorporation of $\left[{ }^{2} \mathrm{H}_{3} \mathrm{C}-\mathrm{S} 4^{\prime}, 5^{\prime}, 6^{\prime}, 7^{\prime}-{ }^{2} \mathrm{H}_{4}\right]$ brassinin (1a), $241.0=[\mathrm{M}+1+6]^{+}, 234.9=[\mathrm{M}+1]^{+}, 190.0=\left[\mathrm{M}+6-\mathrm{SC}^{2} \mathrm{H}_{3}\right]^{+}, 187=$ $\left[\mathrm{M}-\mathrm{SCH}_{3}\right]^{+}, 163.0=\left[\mathrm{M}+6-\mathrm{HNCSC}^{2} \mathrm{H}_{3}\right]^{+}, 160.0=\left[\mathrm{M}-\mathrm{HNCSCH}_{3}\right]^{+}$.

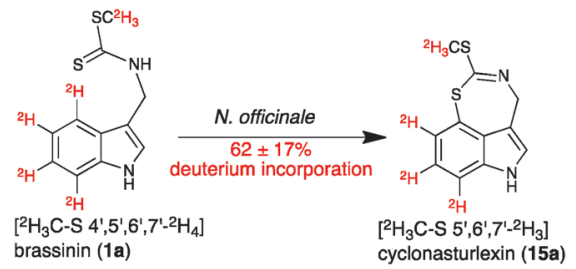

Scheme 4 Transformation of $\left[^{2} \mathrm{H}_{3} \mathrm{C}-\mathrm{S} \quad 4^{\prime}, 5^{\prime}, 6^{\prime}, 7^{\prime}{ }^{2} \mathrm{H}_{4}\right]$ brassinin (1a) to cyclonasturlexin (15a) in elicited leaves of watercress (percentage of deuterium incorporated shown in Table 2).

elicited leaves. As well, because the concentration of cyclonasturlexin $(\mathbf{1 5}+\mathbf{1 5 c})$ in elicited leaves incubated with $(S)-\left[{ }^{13} \mathrm{C}_{11},{ }^{15} \mathrm{~N}_{2}\right] \operatorname{Trp}$ was about four-fold lower than that in elicited leaves incubated with $\mathbf{1 a}$ or $\mathbf{1 b}$, it is likely that brassinin (1) biosynthesis is the rate determining step in the biosynthetic pathway of cyclonasturlexin (15). The small amount of hexadeuterated cyclonasturlexin detected in extracts of non-elicited leaves incubated with $\left[{ }^{2} \mathrm{H}_{3} \mathrm{C}-\mathrm{S} 4^{\prime}, 5^{\prime}, 6^{\prime}, 7^{\prime}-{ }^{2} \mathrm{H}_{4}\right]$ brassinin suggests that there is a residual amount of the "dedicated" enzyme in non-elicited leaves.

The overall results suggest that the intramolecular cyclization of brassinin (1) is catalysed by an inducible enzyme that is regioselective, i.e. it catalyses the oxidative $\mathrm{C}-\mathrm{S}$ coupling of C-4 to produce cyclonasturlexin (15), as a replacement for cyclobrassinin (4). Indeed, recently, two new CYP enzymes, CYP71CR2 and CYP71CR1, were reported to catalyse the cyclization of brassinin (1) to cyclobrassinin (4) and spirobrassinol, respectively, although none of these enzymes were detected in watercress. ${ }^{11}$ As shown in our current work, this finding is not surprising since watercress biosynthesizes cyclonasturlexin (15), but not cyclobrassinin (4). It is worthy of note that CYP71CR2 and CYP71CR1 are the first enzymes reported to be involved in the biosynthesis of a phytoalexin from edible crucifers. Previously, only enzymes of the camalexin pathway operating in the model crucifer species Arabidopsis thaliana were reported. It appears to be very likely that these CYP enzymes are specific to particular crucifer species to facilitate their selective responses to stress caused by fungal phytopathogens such as A. brassicicola. Further work is underway to test the biological activity of cyclonasturlexin against plant pathogens of crucifer species. Nonetheless, considering the results obtained so far, cyclonasturlexin (15) has enormous potential to expand and improve the chemical defence arsenal of crucifer crops.

To conclude, benzo-fused benzothiazepines, counterparts of indole-fused thiazepine 15, are an important class of therapeutic drugs used as antifungals, calcium channel blockers and antidepressants. ${ }^{12}$ Definitely, the unique heterocyclic system of cyclonasturlexin (15) could be a "privileged heterocyclic scaffold" to develop agrochemicals and pharmaceuticals, thus further screening of additional antifungal and pharmacological activities is warranted.

We thank the Natural Sciences and Engineering Research Council of Canada (Discovery Research Grant to MSCP), the Canada Research Chairs Program, the Canada Foundation for Innovation and the University of Saskatchewan (CGSR graduate scholarship to HT) for generous support. K. Thoms and K. Brown of the Department of Chemistry and Saskatchewan Structural Sciences Centre (SSSC) are acknowledged for technical assistance in HREI-MS and NMR determinations, and J. Zhu of SSSC for carrying out X-ray crystallographic analysis of $\mathbf{1 5 .}$

\section{Notes and references}

1 H. D. VanEtten, J. W. Mansfield, J. A. Bailey and E. E. Farmer, Plant Cell, 1994, 6, 1191.

2 M. S. C. Pedras, E. E. Yaya and E. Glawischnig, Nat. Prod. Rep., 2011, 28, 1381.

3 M. S. C. Pedras and E. E. Yaya, Org. Biomol. Chem., 2012, 10, 3613.

4 S. I. Warwick, in Brassicaceae in Agriculture, ed. R. Schmidt and I. Bancroft, Springer Science, 2011, p. 33.

5 M. S. C. Pedras and Q. H. To, Phytochemistry, 2015, 113, 57.

6 X.-B. Xu, J. Liu, J.-J. Zhang and Y.-W. Wang, and Y. Peng, Org. Lett., 2013, 15, 550.

7 K. Kato, M. Ono and H. Akita, Tetrahedron, 2001, 57, 10055.

8 L. Shi, X. Liu, H. Zhang, Y. Jiang and D. Ma, J. Org. Chem., 2011, 76, 4200 .

9 S. Murru, H. Ghosh, S. K. Sahoo and B. K. Patel, Org. Lett., 2009, 11, 4254.

10 M. S. C. Pedras, P. B. Chumala, W. Jin, M. S. Islam and D. W. Hauck, Phytochemistry, 2009, 70, 394.

11 A. P. Klein and E. S. Sattely, Nat. Chem. Biol., 2015, 11, 837.

12 D. Saha, G. Jain and A. Sharma, RSC Adv., 2015, 5, 70619. 